\title{
ANTICORPOS CONTRA Toxoplasma gondii EM ESTUDANTES DE MEDICINA VETERINÁRIA DE CAMPO GRANDE, MS, BRASIL
}

\author{
ANTIBODIES TO Toxoplasma gondii IN VETERINARY MEDICINE STUDENTS OF CAMPO \\ GRANDE, MS, BRAZIL
}

\author{
Flábio Ribeiro de Araújo ${ }^{1}$ Enio Cesar Sarti $^{1}$ Adalberto José Crocci $^{2}$ Viviane Maria Souza Seabra $^{3}$ \\ Jan Heber Amorim ${ }^{3}$ Flávia Queiróz Cusinato ${ }^{3}$ Cristina Pires de Araújo ${ }^{3}$ \\ Cristiano Marcelo Espinola Carvalho ${ }^{3}$
}

RESUMO

Amostras de soro obtidas de estudantes do curso de Medicina Veterinária da Universidade para o Desenvolvimento do Estado e da Região do Pantanal, Campo Grande, MS, Brasil, foram examinadas para a presença de anticorpos contra Toxoplasma gondii. Dos 145 soros testados, 44 (30,34\%) foram positivos na hemaglutinação, com título igual ou superior a 1:16. Não foram observadas associações entre as características epidemiológicas examinadas, tais como hábitos alimentares (ingestão de carne bovina crua ou malpassada, vegetais crus/não lavados, produtos lácteos não pasteurizados) ou contato constante com cães e a presença de anticorpos contra $\boldsymbol{T}$. gondii, exceto pelo percentual significativamente maior de estudantes soropositivos que relataram ter contato freqüente com gatos $(P=0,03)$.

Palavras-chave: toxoplasma, levantamento sorológico, estudantes, medicina veterinária.

\section{SUMMARY}

Serum samples obtained from students of the Schoo of Veterinary Medicine, Universidade para o Desenvolvimento do Estado e da Região do Pantanal, Campo Grande, MS, Brazil, were examined for Toxoplasma gondii antibodies. Serum samples from $44(30.34 \%)$ of the 145 veterinary students examined were positive on the hemagglutination test, yielding a titer of 1:16 or greater. There were no relations between the epidemiological characteristics examined, such as food habits (eating of raw or rare-cooked cattle meat, raw/uncleaned vegetables, unpasteurized dairy products), frequent contact with dogs and the presence of $\boldsymbol{T}$. gondii antibodies, except for a significantly higher percentual of seropositive students that reported frequent contact with cats $(\mathrm{P}=0.03)$.
Key words: toxoplasma, serological survey, students, veterinary medicine

\section{INTRODUÇÃO}

A toxoplasmose é uma antropozoonose causada pelo protozoário Toxoplasma gondii. Os felídeos constituem os hospedeiros definitivos, enquanto que aves e mamíferos, incluindo o homem, são hospedeiros intermediários (HASHEMIFRESHARKI, 1996). No homem, a maioria das infecções é assintomática, porém a toxoplasmose em pacientes comprometidos imunologicamente e no feto é uma doença grave ou até mesmo fatal (WONG \& REMINGTON, 1993). Considera-se que as três principais formas de transmissão do $\boldsymbol{T}$. gondii seriam pela ingestão de oocistos, eliminados pelo gato, que contaminam o solo e os alimentos, pelo consumo de carnes e/ou vísceras malcozidas contendo cistos e pela via transplacentária (VIDOTTO, 1991). Também assume-se que profissionais expostos ao contato freqüente com animais, como os médicos veterinários, estariam submetidos a um maior risco de adquirir a infecção (URQUHART $\boldsymbol{e t} \boldsymbol{a l}$, 1998).

Neste contexto, foi realizado um inquérito para determinar a prevalência de estudantes de Medicina Veterinária com sorologia positiva para $\boldsymbol{T}$. gondii em Campo Grande, MS, Brasil (Universidade para o Desenvolvimento do Estado e da Região do

\footnotetext{
${ }^{1}$ Médico Veterinário. Professor do Centro de Ciências Biológicas Agrárias e da Saúde. Universidade para o Desenvolvimento do Estado e da Região do Pantanal (UNIDERP). Rua Alexandre Herculano, 1400, Campo Grande, MS, CEP: 7937-2801. E-mail: flabioaraujo@ hotmail.com

${ }^{2}$ Estatístico. Departamento de Bioestatística do Instituto de Biociências da UNESP, Campus de Botucatu

${ }^{3}$ Estudantes de Medicina Veterinária da UNIDERP
} 
Pantanal-UNIDERP), bem como identificar hábitos e comportamentos de risco para infecção por este protozoário.

\section{MATERIAL E MÉTODOS}

O levantamento sorológico foi realizado em 145 voluntários adultos, que assinaram um termo de ciência dos objetivos do estudo. Um questionário sobre os hábitos alimentares (consumo de produtos lácteos bovinos não pasteurizados, carne bovina crua ou malpassada, vegetais crus ou não lavados) e contato freqüente com felinos e caninos (indivíduos que possuem esses animais ou freqüentemente entram em contato na Universidade ou em clínicas) foi respondido pelos acadêmicos.

Amostras de sangue foram colhidas por punção venosa em tubos a vácuo sem anticoagulante e os soros, obtidos após centrifugação do coágulo, foram armazenados a $-20^{\circ} \mathrm{C}$, em duplicata. Antes das análises, os soros foram mantidos a $56^{\circ} \mathrm{C}$ por 30 minutos para inativação do complemento e, então, foram analisados por hemaglutinação indireta, utilizando eritrócitos de galinha sensibilizados com antígenos de $\boldsymbol{T}$. gondii, segundo o protocolo do fabricante (Biolab). Foi feita uma triagem dos soros a uma diluição inicial de 1:16 e aqueles positivos foram novamente testados até 1:256.

As análises estatísticas para avaliar a associação entre sorologia positiva para $\boldsymbol{T}$. gondii e a ingestão de produtos de origem animal/vegetal ou o contato freqüente com cães e gatos foram feitas pelo teste do qui-quadrado, enquanto a associação entre ingestão de carne bem ou malpassada e a sorologia positiva foi determinada pelo teste de GOODMAN (1965). Ambos os testes foram realizados com nível de confiança de $95,00 \%$. trabalhadores de Guarulhos, SP (65,80\%); FERRARONI et al. (1982) em cinco populações humanas distintas da Amazônia brasileira (56,20 a 73,90\%); REY \& RAMALHO (1999), na população de Fortaleza, Ceará (22,80 a 71,50\%).

Com relação aos hábitos alimentares dos estudantes, não houve correlação entre a ingestão de produtos lácteos não pasteurizados, quibe cru, vegetais crus ou não lavados e a presença de anticorpos contra $\boldsymbol{T}$. gondii (Tabela 1). Embora a ingestão de alimentos de origem animal e/ou vegetal inapropriadamente preparados seja apontada como uma das formas de disseminação da toxoplasmose para o homem, este estudo não indicou tal associação.

Não houve associação entre a ingestão de carne bovina malpassada e soropositividade para $\boldsymbol{T}$. gondii (Tabela 1). Estudos têm demonstrado que os bovinos não são hospedeiros favoráveis para esse parasito, provavelmente devido à rápida eliminação do $\boldsymbol{T}$. gondii dos tecidos desses animais (DUBEY \& THULLIEZ, 1993), podendo esse fato explicar os resultados obtidos. Reforçando essa teoria, encontrou-se uma baixa prevalência de bovinos de corte soropositivos para T. gondii (4,29\%) no Estado de Mato Grosso do Sul (ARAÚJO et al., 1998). Além desses trabalhos, também não foi encontrada relação entre a ingestão de carne malpassada e sorologia positiva para $\boldsymbol{T}$. gondii em estudantes e empregados da Faculdade de Medicina Veterinária da Universidade de Iowa, EUA (ZIMMERMANN, 1976). No Brasil, CAMARGO et al. (1995) também não encontraram associação entre consumo de carne, leite e ovos e infecção por $\boldsymbol{T}$. gondii.

Não houve associação entre o contato freqüente dos estudantes de Medicina Veterinária com cães e soropositividade para $\boldsymbol{T}$. gondii (Tabela 2). No entanto, o percentual de estudantes soropositivos que entrou em contato frequientemente com felinos foi estatisticamente superior $(\mathrm{P}=0,03)$ ao percentual

\section{RESULTADOS E DISCUSSÃO}

Das 145 amostras de soro analisadas, $44 \quad(30,34 \%)$ foram positivas para anticorpos contra T. gondii. Destes, 5 $(11,36 \%)$ tiveram um título de anticorpos de 1:16, $2(4,55 \%)$ de $1: 32,5(11,36 \%)$ de $1: 128$ e 32 $(72,73 \%) \geq 1: 256)$. Essa prevalência foi inferior às estimativas de infecção da população mundial, que está em torno de $40,00 \%$ (McKERROW \& HEYNEMAN, 1994). Também foi inferior ou semelhante às freqüências descritas em outros estudos conduzidos no Brasil, como o de LANZARINI et al. (1982) em
Tabela 1 - Hábitos alimentares dos estudantes do curso de Medicina Veterinária da UNIDERP, Campo Grande, MS, Brasil, e presença de anticorpos contra Toxoplasma gondii.

\begin{tabular}{|c|c|c|c|c|c|c|}
\hline \multirow[t]{2}{*}{ Produto ingerido } & \multicolumn{6}{|c|}{ Número de estudantes (\%) } \\
\hline & \multicolumn{2}{|c|}{ Total } & \multicolumn{2}{|c|}{ Soropositivos } & \multicolumn{2}{|c|}{ Soronegativos } \\
\hline Leite bovino não pasteurizado & $16 / 145$ & $(11,03)$ & $6 / 44$ & $(13,64)$ & $10 / 101$ & $(9,90)$ \\
\hline $\begin{array}{l}\text { Manteiga/queijo não pasteuri- } \\
\text { zado (leite bovino) }\end{array}$ & $88 / 145$ & $(60,69)$ & $28 / 44$ & $(63,64)$ & $60 / 101$ & $(59,41)$ \\
\hline Vegetais crus & $117 / 145$ & $(80,69)$ & $36 / 44$ & $(81,82)$ & $81 / 101$ & $(80,20)$ \\
\hline Vegetais não lavados & $16 / 145$ & $(11,03)$ & $6 / 44$ & $(13,64)$ & $10 / 101$ & $(9,90)$ \\
\hline Quibe cru (carne bovina) & $53 / 145$ & $(36,55)$ & $16 / 44$ & $(36,36)$ & $37 / 101$ & $(36,63)$ \\
\hline Carne bovina bem passada & $1105 / 145$ & $(72,41)$ & $35 / 44$ & $(79,55)$ & $70 / 101$ & $(69,31)$ \\
\hline Carne bovina malpassada & $36 / 145$ & $(24,83)$ & $7 / 44$ & $(15,91)$ & $29 / 101$ & $(28,71)$ \\
\hline $\begin{array}{l}\text { Carne bovina bem e malpas- } \\
\text { sada }\end{array}$ & $3 / 145$ & $(2,07)$ & $2 / 44$ & $(4,55)$ & $1 / 101$ & $(0,99)$ \\
\hline Vegetariano & $1 / 145$ & $(0,69)$ & 0 & $(0,00)$ & 1 & $(0,99)$ \\
\hline
\end{tabular}


Tabela 2 - Contato frequiente com felinos e caninos por estudantes do curso de Medicina Veterinária da UNIDERP, Campo Grande, MS, Brasil, e presença de anticorpos contra Toxoplasma gondii.

\begin{tabular}{|c|c|c|c|c|}
\hline \multirow[t]{2}{*}{ Espécie } & \multicolumn{4}{|c|}{ Número de estudantes (\%) } \\
\hline & & & Soropositivos & Soronegativos \\
\hline Canina & $125 / 145$ & $(86,21)$ & $(77,27)$ & $(90,10)$ \\
\hline Felina & $43 / 145$ & $(29,66)$ & $(43,18)^{\mathrm{a}}$ & $(23,76)^{b}$ \\
\hline
\end{tabular}

$\mathrm{a}<\mathrm{b} \quad(\mathrm{P}=0,03)$

observado no grupo dos soronegativos, indicando que a exposição aos felinos é um fator de risco importante na infecção por esse protozoário. Esses dados assemelham-se aos estudos realizados por CAMARGO et $\boldsymbol{a l}$. (1995) e REY \& RAMALHO (1999), que encontraram uma associação entre o contato freqüente com gatos e a infecção por $\boldsymbol{T}$. gondii. No entanto, diferem de outros estudos (SENGBUSCH \& SENGBUSCH, 1976; ZIMMERMANN, 1976; DiGIACOMO et al., 1990), nos quais não foi encontrada uma associação significativa entre a exposição de empregados e/ou estudantes de faculdades de Medicina Veterinária aos felinos e a prevalência de anticorpos contra $T$. gondii. Essas divergências podem estar associadas às diferenças na duração da exposição e entre os hábitos de higiene pessoal (SENGBUSCH \& SENGBUSCH, 1976). Sabe-se que a lavagem das mãos após a manipulação de animais ou a utilização de luvas reduz a possibilidade de infecção por este protozoário (DUBEY, 1996).

\section{CONCLUSÕES}

Os resultados obtidos neste estudo sugerem que provavelmente os estudantes de Medicina Veterinária não estão expostos a um risco maior que o restante da população de adquirir a toxoplasmose.

Em relação às formas de transmissão da toxoplasmose, esse estudo sugere que o principal fator de risco para infecção por $\boldsymbol{T}$. gondii seria o contato freqüente com gatos, parecendo não existir uma associação entre a ingestão de carne e leite bovino e derivados e/ou vegetais preparados de forma inapropriada e a infecção por $\boldsymbol{T}$. gondii.

\section{REFERÊNCIAS BIBLIOGRÁFICAS}

ARAúJO, F.R., CARVALHO, C.M.E., BALBUENA, C.B. Levantamento sorológico para Toxoplasma gondii em bovinos de corte do Estado de Mato Grosso do Sul, Brasil. Revista Brasileira de Medicina Veterinária, v.20, n.5, p.201203, 1998.
CAMARGO, M.C.V., ANTUNES, C.M.F., CHIARI, C.A. Epidemiologia da infecção por Toxoplasma gondii no Munícipio de Ribeirão das Neves, MG.: 1- Importância dos animais domésticos como fonte de infecção do $\boldsymbol{T}$. gondii para o homem. Revista da Sociedade Brasileira de Medicina Tropical, v.28, n.3, p.211-214, 1995.

DiGIACOMO, R.F., HARRIS, N.V., HUBER, N.L. et al. Animal exposure and antibodies to Toxoplasma gondii in a university population. American Journal of Epidemiology, v.131, n.4, p.729-733, 1990.

DUBEY, J.P., THULLIEZ, P. Persistence of tissue cysts in Edible tissues of cattle fed Toxoplasma gondii oocysts. American Journal of Veterinary Research, v.54, n.2, p.270-273, 1993.

DUBEY, J.P.. Strategies to reduce transmission of Toxoplasma gondii to animals and humans. Veterinary Parasitology, v.64, p.65-70,1996.

FERRARONI, J.J., LACAZ, C.S. Prevalência de anticorpos contra os agentes causadores da hepatite, malária, sífilis e toxoplamose em cinco populações humanas distintas da Amazônia Brasileira. Revista do Instituto de Medicina Tropical de São Paulo, v.24, n.3, p.155-161, 1982.

GOODMAN, L.A. On simultaneous confidence intervals for multinomial proportions. Technometrics, v.7, p.247-254, 1965.

HASHEMI-FRESHARKI, R. Seroprevalence of Toxoplasma gondii in cattle, sheep and goats in Iran. Veterinary Parasitology, v.61, p.1-3, 1996.

LANZARINI, I.E., MARIONI FILHO, H., KAWARABAYASHI, M., et al. Toxoplasmose: inquérito sorológico entre trabalhadores do município de Guarulhos - Estado de São Paulo. Revista do Instituto de Medicina Tropical de São Paulo, v.24, n.1, p.56-59, 1982.

McKERROW, J., HEYNEMAN, D. Parasitic diseases. In: STITES D.P., TERR, A.I., PARSLOW T.G. Basic \& clinical immunology. 8.ed. London : Prentice-Hall; 1994. p.666679.

REY, L.C., RAMALHO, I.L. Seroprevalence of toxoplasmosis in Fortaleza, Ceará, Brazil. Revista do Instituto de Medicina Tropical de São Paulo, v.41, n.3, p.171-174, 1999.

SENGBUSCH, H.G., SENGBUSCH, L.A. Toxoplasma antibodies in veterinary personnel and a selected population not exposed to cats. American Journal of Epidemiology, v.103, n.6, p.595-597, 1976.

URQUHART, G.M., ARMOUR, J., DUNCAN, J.L. et al. Parasitologia veterinária. 2.ed. Rio de Janeiro : Guanabara Koogan, 1998. 273p.

VIDOTTO, O. Toxoplasmose: epidemiologia e importância da doença na saúde animal. In: SEMINÁRIO BRASILEIRO DE PARASITOLOGIA VETERINÁRIA, 7, 1991, São Paulo, SP. Anais.... São Paulo, SP : Colégio Brasileiro de Parasitologia Veterinária; 1991. p.80-94.

WONG, S.Y., REMINGTON, J.S. Biology of Toxoplasma gondii. AIDS, v.7, n.3, p.299-316, 1993.

ZIMMERMANN, W.J. Prevalence of Toxoplasma gondii antibodies among veterinary college staff and students, Iowa Sate University. Public Health Reports, v.91, n.6, p.526532, 1976. 